\title{
Testing for anti-p53 antibodies increases the diagnostic sensitivity of conventional tumor markers
}

\author{
MARTINA MÜLLER ${ }^{1}$, MARTINA MEYER $^{1}$, TOBIAS SCHILLING ${ }^{2}$, ERNST ULSPERGER ${ }^{3}$, THOMAS LEHNERT ${ }^{4}$, \\ HANSWALTER ZENTGRAF ${ }^{5}$, WOLFGANG STREMMEL ${ }^{1}$, MARTIN VOLKMANN ${ }^{6 *}$ and PETER R. GALLE ${ }^{7 *}$ \\ Departments of ${ }^{1}$ Internal Medicine IV, Hepatology and Gastroenterology and ${ }^{2}$ Internal Medicine I, Endocrinology and \\ Clinical Chemistry, University of Heidelberg, Im Neuenheimer Feld 410, D-69120 Heidelberg, Germany; ${ }^{3}$ Department of \\ Internal Medicine 5, Oncology, Hospital Hietzing, Wolkersbergenstrasse 1, 1130 Vienna, Austria; ${ }^{4}$ Department of Surgery, \\ Klinikum Bremen-Mitte, St.-Jürgen-Str. 1, D-28205 Bremen; ${ }^{5}$ Applied Tumor Virology, German Cancer Research Center, \\ Im Neuenheimer Feld 280, D-69120 Heidelberg; ${ }^{6}$ Labor Prof. Seelig \& Kollegen, Kriegsstrasse 99, D-76133 Karlsruhe; \\ ${ }^{7}$ I. Department of Medicine, Johannes Gutenberg University Mainz, Langenbeckstr. 1, D-55131 Mainz, Germany
}

Received April 12, 2006; Accepted June 14, 2006

\begin{abstract}
The aim of this study was to determine whether anti-p53 antibodies are of clinical significance as a serological marker in the diagnosis and monitoring of malignancies. A total of 1874 serum samples from 591 patients with various types of cancer, esophageal, gastric, colorectal, pancreatic, hepatocellular, breast, and urogenital cancer, and 436 control individuals were analyzed by immunoblot for antibodies against p53. The anti-p53 antibody test was correlated with expression of conventional tumor markers, survival and the clinicopathological features of malignant disease. Anti-p53 antibodies were found in $23.4 \%(138 / 591)$ of the sera of patients with malignant disease (range 11.5-34\%). The detection of anti-p53 serum antibodies had a specificity of $100 \%$ for malignancy $(\mathrm{p}<0.0001)$. The overall sensitivity of measuring established tumor markers was $62.9 \%$ (372/591). The elevation of conventional tumor markers and the presence of anti-p53 antibodies in the sera of patients with malignant disease turned out to be an independent variable $(\mathrm{p}<0.05)$. Combination of established tumor markers with the anti-p53 antibody test led to an increase in diagnostic sensitivity of $8 \%(49 / 591)(\mathrm{p}<0.01)$. Thus, the independence of anti-p53 antibodies from established tumor markers allows the serological detection of additional tumor patients. Kaplan-Meier
\end{abstract}

Correspondence to: Dr Martina Müller, Department of Internal Medicine IV, Hepatology and Gastroenterology, University of Heidelberg, Im Neuenheimer Feld 410, D-69120 Heidelberg, Germany

E-mail: martina_mueller-schilling@med.uni-heidelberg.de

\section{*Shared senior authorship}

Key words: p53, anti-p53 antibodies, survival, prognosis, follow-up analysis revealed a trend toward a poorer prognosis in hepatocellular carcinoma and breast cancer patients who were anti-p53 serum positive. In conclusion, testing for anti-p53 antibodies can increase the diagnostic sensitivity when used in combination with measurement of conventional tumor markers. This increase is achieved without a parallel decrease in specificity.

\section{Introduction}

Mutations in the p53 gene are the most common genetic alterations in human cancers (1-3). Most of the known p53 gene alterations are missense mutations clustered in the evolutionary highly conserved exons 4-8 (4,5). Mutant forms can act as dominant oncogenes, whereas wild-type p53 has characteristics of a recessive tumor-suppressor gene (6-9). Wild-type p53 resides in the cell nucleus and has a very short half-life (10). Mutant p53 characteristically has an increased half-life, resulting in nuclear accumulation. Thus, detection of increased nuclear levels of p53 is indicative of cancers that harbor mutant p53 (8). Proteins that are overexpressed by tumor cells or that accumulate in tumor cells are more readily available for immune recognition than the same proteins expressed at basal levels in non-cancerous cells (11).

P53 has been shown to be a possible target of the immune system. Antibodies against p53 have been detected in different tumor entities with an incidence ranging from 10 to $30 \%$ (12-19) and are usually associated with the accumulation of the mutant p53 protein in the tumor $(19,20)$ - due presumably to the conformational alterations produced by the mutations that cause it to be identified as foreign by the body's immune response (21). Although p53 gene mutation or p53 protein overexpression does not automatically lead to a humoral immune response, anti-p53 antibodies have been found in serum only when p53 accumulation was detected in the malignant tumor (22). The anti-p53 antibody response is directed mainly against the amino and carboxy regions of the p53 protein (23), rather than at the central mutational hot spot region (residue 117-286) $(15,24-27)$. 
It has been hypothesized that antibodies directed against p53 may serve as serological marker in the clinical management of patients in whom they have been detected. Furthermore, there is ongoing controversy on a possible association of circulating p53 antibodies with criteria associated with prognosis.

To address these issues, we investigated the clinical usefulness of anti-p53 serum antibodies for diagnosis and monitoring of cancer patients. In this study, the expression of p53 antibodies was correlated with established tumor markers and clinicopathological features of malignant disease. In addition, the predictive role of these antibodies regarding relapse and overall survival was analyzed.

\section{Patients and methods}

Patients and study design. The study comprised 591 patients with various histologically defined malignant diseases and 436 control individuals. The mean age $( \pm \mathrm{SD})$ of the patients suffering from cancer was $58.8 \pm 11.4$ years [sex $(M / F)$ : $366 / 225$ ], the mean age of the control patients was $48.4 \pm 15.3$ years [sex (M/F): 212/224]. With the exception of 100 patients in the colon cancer group (please see below), all patients had been seen at the University of Heidelberg. The patients were consecutive patients who had been admitted to the medical department of the University of Heidelberg and patients who had been treated in the oncology clinic. Eligibility criteria of the patients who entered the study were diagnoses of malignant disease based on histological examination. There were 197 patients who suffered from colon cancer, 80 from hepatocellular carcinoma (HCC) [data of this patient cohort have partially been published before (16)], 50 from breast cancer, 22 from pancreatic cancer, 46 from rectal cancer, 24 from urogenital cancer and 122 from gastric cancer.

Follow-up examinations were performed in the patients who were treated in the oncology clinic and in the department of Internal Medicine of the University of Heidelberg. Patients who went back to their referring hospitals for further monitoring and chemotherapy were not included in the longitudinal study. In total, follow-up examinations were performed in 303 of the 591 patients with malignant disease.

The mean age $( \pm \mathrm{SD})$ of the follow-up patients was $57.8 \pm 11.4$ years [sex (M/F): 179/124] compared to $59.8 \pm 11.4$ years [sex (M/F): 187/101] of the population of patients who did not supply follow-up blood samples. The subset selected for follow-up and the subset excluded from the longitudinal study, did not differ concerning their age, sex, tumor stage, tumor grading, tumor nodes and tumor metastases. The median observation time was 188 days (minimum 1 day, maximum 1462 days).

Follow-up examinations were performed up to 16 times per patient with a median of 3 follow-up examinations. In total 1438 sera were tested. All sera were stored at $-70^{\circ} \mathrm{C}$ until used.

In the colon cancer group, 100 patients had been enrolled in a multicenter, prospective, randomized trial involving nine different surgical departments in Vienna. After resection of colorectal cancer at stage Dukes C, patients were followed-up to 5 years. Follow-up included clinical status, current weight, chest-X-ray, recto- or coloscopy, liver ultrasonography and blood testing, including tumor markers, every 3 months for 2 years and subsequently in half-year intervals up to 5 years postoperatively.

Control sera were obtained from 379 patients who routinely attended the liver and endocrinology clinic at our institution. The inclusion criterion for these patients was no history or diagnosis of known or suspected neoplasm. Since the assay was evaluated as a screening test, we furthermore tested the sera of 57 healthy individuals for the occurence of anti-p53 antibodies to rule out the possibility that patients in the liver and endocrinology clinics might have impaired immune systems such that the study would be biased toward a higher specificity.

Routine investigations. Levels of established tumor markers were determined for the different tumor entities: B-human chorionic gonadotropin (HCG), alpha-fetoprotein (AFP) and squamous cell carcinoma (SCC) were measured using a microparticle enzyme immunoassay (Abbott GmbH Diagnostika, Wiesbaden-Delkenheim, Germany). Carcinoembryonic antigen (CEA), carbohydrate antigen 19-9 (CA19-9), cancer antigen 15-3 (CA15-3) and cancer antigen 72-4 (CA72-4) were determined using an ELISA (Enzymun-Test, Boehringer Mannheim, Mannheim, Germany). The normal ranges were as follows: AFP $(<20 \mathrm{ng} / \mathrm{ml}), \mathrm{SCC}(<2.5 \mathrm{ng} / \mathrm{ml}), \mathrm{CEA}$ $(<2.5 \mathrm{ng} / \mathrm{ml})$, CA19-9 $(<37 \mathrm{U} / \mathrm{ml})$, CA15-3 $(<25 \mathrm{U} / \mathrm{ml})$, CA72-4 $(<3 \mathrm{U} / \mathrm{ml})$. The patients were graded positive when the test result exceeded these ranges.

P53 immunoblot analysis. Recombinant p53 was used as antigen in an immunoblot assay as described previously (16). In brief, Western blotting was carried out with $100 \mathrm{ng}$ recombinant p53 per lane. Proteins were separated by means of polyacrylamide gel electrophoresis (10\% acrylamide). The proteins were transferred to a nitrocellulose membrane using the BioRad electrotransfer system. Filters were cut into strips and further processed according to the Western-Light ${ }^{\mathrm{TU}}$ protocol (Tropix, Bedford, MA, USA). Patient sera were tested at a 1:100 dilution. The mouse IgG monoclonal antibody PAb 1801 (Dianova, Hamburg, Germany) was used as positive control.

Statistical analysis. Statistical analysis was carried out using the SAS software system (SAS Institute Inc., Cary, NC, USA). The independence between anti-p53 antibodies and measurement of established tumor markers was tested by McNemar's method. The estimated survival time was calculated by the Kaplan-Meier method and the differences of estimated survival time between groups were analyzed by log-rank and Wilcoxon test.

In patients with colon cancer $\chi^{2}$ test for contingency tables with ordered categories was used to test the relationships between anti-p53 antibody production and clinical parameters such as grade of differentiation and Dukes stage. Cox regression analysis of factors potentially related to survival was performed to identify which independent factors would jointly have a significant influence on survival of patients suffering from colon cancer. Cox's proportional hazards model was used to test the relationship of an anti-p53 antibody response, grade of differentiation, Dukes stage, and histology to prognosis. 
Table I. Frequency of anti-p53 antibodies in the sera of patients with different tumor types.

\begin{tabular}{lccccccccc}
\hline Anti-p53 ab & $\begin{array}{c}\text { Esophagus } \\
(\mathrm{n}=50)\end{array}$ & $\begin{array}{c}\text { Gastric } \\
(\mathrm{n}=122)\end{array}$ & $\begin{array}{c}\text { Colon } \\
(\mathrm{n}=197)\end{array}$ & $\begin{array}{c}\text { Rectum } \\
(\mathrm{n}=46)\end{array}$ & $\begin{array}{c}\text { Pancreas } \\
(\mathrm{n}=22)\end{array}$ & $\begin{array}{c}\mathrm{HCC}^{\mathrm{b}} \\
(\mathrm{n}=80)\end{array}$ & $\begin{array}{c}\text { Breast } \\
(\mathrm{n}=50)\end{array}$ & $\begin{array}{c}\text { Urogenital } \\
(\mathrm{n}=24)\end{array}$ & $\begin{array}{c}\text { Total } \\
(\mathrm{n}=591)\end{array}$ \\
\hline Negative & 40 & 108 & 134 & 39 & 17 & 61 & 33 & 21 & 453 \\
& & & & & & & & & \\
Positive & 10 & 14 & 63 & 7 & 5 & 19 & 17 & 3 & 138 \\
$(\%)$ & $(20)$ & $(11.5)$ & $(32)$ & $(15.2)$ & $(22.7)$ & $(23.8)$ & $(34)$ & $(12.5)$ & $(23.4)$ \\
\hline
\end{tabular}

${ }^{\mathrm{a} A n t i-p 53}$ antibodies; bhepatocellular carcinoma.

Table II. Results of the anti-p53 serum antibody test.

\begin{tabular}{lccr}
\hline & \multicolumn{2}{c}{ Anti-p53 antibody test } & \\
\cline { 2 - 3 } Frequency & Positive & Negative & Total \\
\hline Malignant disease & 138 & 453 & 591 \\
& $(23.4 \%)^{\mathrm{a}}$ & & \\
Non-malignant disease & 0 & 436 & 436 \\
& & $(100 \%)^{\mathrm{b}}$ & \\
Total & 138 & 889 & 1027 \\
\hline aSensitivity; ${ }^{\text {b }}$ specificity: $\mathrm{p}<0.0001$ (Fisher's exact test, 2-tail). \\
\hline
\end{tabular}

Both, grade of differentiation and Dukes stage were treated as continuous variables (categories coded 1,2,3). In multivariate analysis, we also tested for interactions between the above mentioned major parameters. All p-values reported are twosided, and those $<0.05$ were judged statistically significant.

\section{Results}

Anti-p53 antibodies are specific for malignancy. Immunoblotting with purified recombinant p53 as antigen demonstrated the presence of anti-p53 antibodies in $23.4 \%$ (138/591) of the patients with malignant disease. Table I gives an overview of the frequency of anti-p53 antibodies in the sera of patients with different tumor types. Anti-p53 antibodies were found in the sera of patients with all types of malignant disease tested (Table I). However, the frequency/sensitivity of antip53 antibodies differed among patients with various types of cancer, ranging from $11.5 \%(14 / 122)$ in gastric cancer patients up to $32 \%(63 / 197)$ in colon cancer and $34 \%(17 / 50)$ in breast cancer patients.

In contrast, the sera of the patients in the control group, without evidence of malignancy, were all negative for anti-p53 antibodies. Thus, anti-p53 antibodies showed a specificity of $100 \%$ for malignancy (Fisher's two tail exact test: $p<0.0001$, Table II).

Anti-p53 antibodies and established tumor markers are independent variables. All the sera were tested in parallel for the presence of conventional tumor marker(s). Elevated tumor markers were found in $62.9 \%(372 / 591)$ of sera. The range was $0 \%(0 / 24$; lack of adequate tumor marker) in sera from patients with urogenital cancer, $45.5 \%(10 / 22)$ in sera from pancreatic cancer patients, and $86 \%$ (43/50) in sera from breast cancer patients (note: two markers, CEA and CA15-3, were used in combination). Table III summarizes the test results using anti-p53 antibodies in addition to conventional tumor markers. McNemar analysis of the significance of change, examining the independence of the two variables anti-p53 antibodies and elevated tumor markers, revealed a significant difference with a $\chi^{2}$ of 189 for $\mathrm{p}<0.05$. Thus, the presence of anti-p53 antibodies in the sera of patients with malignant disease and the elevation of established tumor markers is an independent variable.

Testing for anti-p53 increases the diagnostic sensitivity of established tumor markers. The combined use of both tests resulted in an increased sensitivity of $71.2 \%$ (421 of 591 patients, Table III). The anti-p53 immunoblot assay identified 31 of 88 CEA-negative patients with colon cancer (35.2\%), five of 21 AFP-negative patients with hepatocellular carcinoma (HCC) (23.8\%), three of seven CA15-3- and CEA-negative patients with breast cancer $(42.8 \%)$, two of 20 SCC-negative patients with esophageal cancer (10\%), one of 12 CA19-9negative patients with pancreatic cancer $(8.3 \%)$, two of ten CEA-negative patients with rectal cancer $(20 \%)$, three of 24 patients with urogenital cancer $(12.5 \%)$ and two of 37 CA72-4-negative patients with gastric cancer (5.4\%).

Since the anti-p53 antibody test has a $100 \%$ specificity, the combination of testing for conventional tumor markers and anti-p53 antibodies leads to an increase in sensitivity in the detection of malignant disease without decreasing the specificity. Overall a gain of information of $8.3 \%$ could be achieved: 49 of 591 patients with malignant disease were identified only after addition of the anti-p53 immunoblot assay. This gain was significant $(\mathrm{p}<0.01)$, with a $95 \%$ confidence interval of $6-11 \%$.

Anti-p53 antibodies and survival. Kaplan-Meier analyses did not reveal a significant difference in survival when comparing the relation between survival of patients with antip53 seropositivity and patients without detectable anti-p53 antibodies. However, Kaplan-Meier analysis demonstrated a trend toward a shorter overall survival for patients with 
Table III. Identification of a subset of tumor marker-negative patients with malignant disease by combined testing for anti-p53 antibodies.

\begin{tabular}{lccccccccc}
\hline Tumor & $\begin{array}{c}\text { Esophagus } \\
(\mathrm{n}=50)\end{array}$ & $\begin{array}{c}\text { Gastric } \\
(\mathrm{n}=122)\end{array}$ & $\begin{array}{c}\text { Colon } \\
(\mathrm{n}=197)\end{array}$ & $\begin{array}{c}\text { Rectum } \\
(\mathrm{n}=46)\end{array}$ & $\begin{array}{c}\text { Pancreas } \\
(\mathrm{n}=22)\end{array}$ & $\begin{array}{c}\mathrm{HCC}^{\mathrm{b}} \\
(\mathrm{n}=80)\end{array}$ & $\begin{array}{c}\text { Breast } \\
(\mathrm{n}=50)\end{array}$ & $\begin{array}{c}\text { Urogenital } \\
(\mathrm{n}=24)\end{array}$ & $\begin{array}{c}\text { Total } \\
(\mathrm{n}=591)\end{array}$
\end{tabular}

Conventional tumor

markers $^{\mathrm{a}}$

$\begin{array}{lccccccccc}\text { Negative } & 20 & 37 & 88 & 10 & 12 & 21 & 7 & 24 & 219 \\ \text { Positive } & 30 & 85 & 109 & 36 & 10 & 59 & 43 & 0 & 372 \\ (\%) & (60) & (69.7) & (55.3) & (78.3) & (45.5) & (73.8) & (86) & (0) & (62.9)\end{array}$

Conventional tumor

markers + anti-p53

\begin{tabular}{lccccccccc} 
Negative & 18 & 35 & 57 & 8 & 11 & 16 & 4 & 21 & 170 \\
Positive & 32 & 87 & 140 & 38 & 11 & 64 & 46 & 3 & 421 \\
$(\%)$ & $(64)$ & $(71.3)$ & $(71.1)$ & $(82.6)$ & $(50)$ & $(80)$ & $(92)$ & $(12.5)$ & $(71.2)$ \\
Information gain & 4 & 1.6 & 15.8 & 4.3 & 4.5 & 6.2 & 6 & 12.5 & 8.3 \\
$(\%)$ & & & & & & & & & \\
\hline
\end{tabular}

aTumors were tested for the following conventional markers: colon, CEA; HCC, AFP; breast, CA 15-3 + CEA; esophagus, SCC; pancreas, CA19-9; rectum, CEA; urogenital, none; gastric, CA72-4. 'Hepatocellular carcinoma.
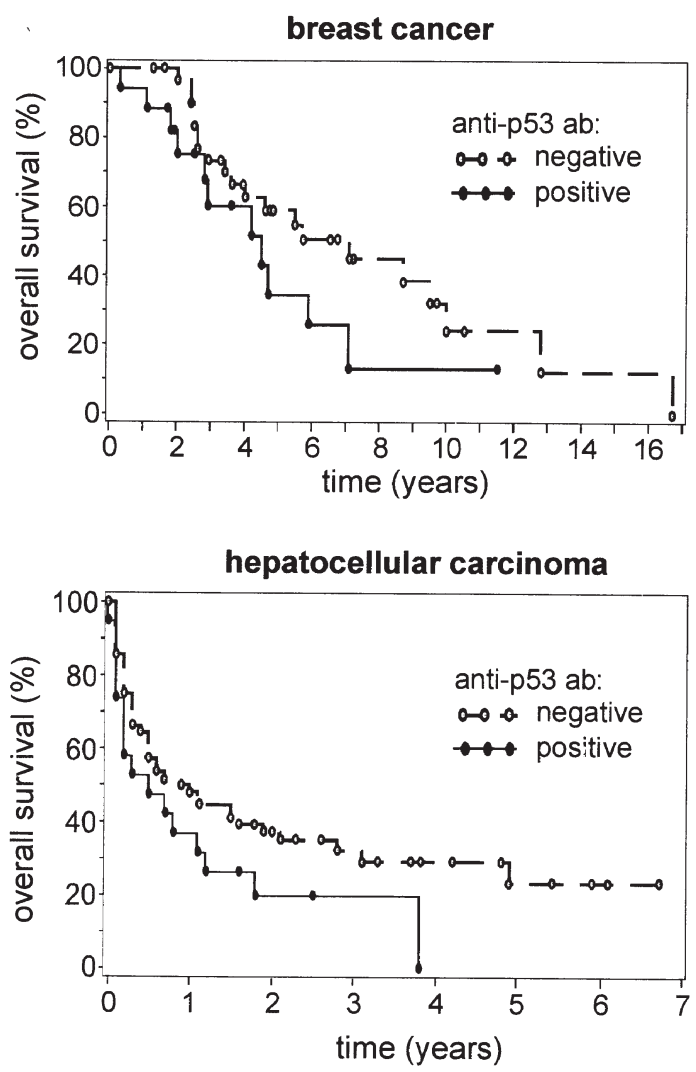

Figure 1. Kaplan-Meier analyses of survival in patients with breast cancer (top) and in patients with hepatocellular carcinoma (HCC) (bottom) with respect to anti-p53 antibody (anti-p53 ab) status. There is a trend towards a shorter survival time in patients with breast cancer (Wilcoxon: $p<0.125$, log-rank: $\mathrm{p}<0.138$ ) and in patients with hepatocellular carcinoma (Wilcoxon: $\mathrm{p}<0.135$, log-rank: $\mathrm{p}<0.098)$ who have developed anti-p53 serum antibodies $(\bullet)$ compared to anti-p53 seronegative patients $(0)$.
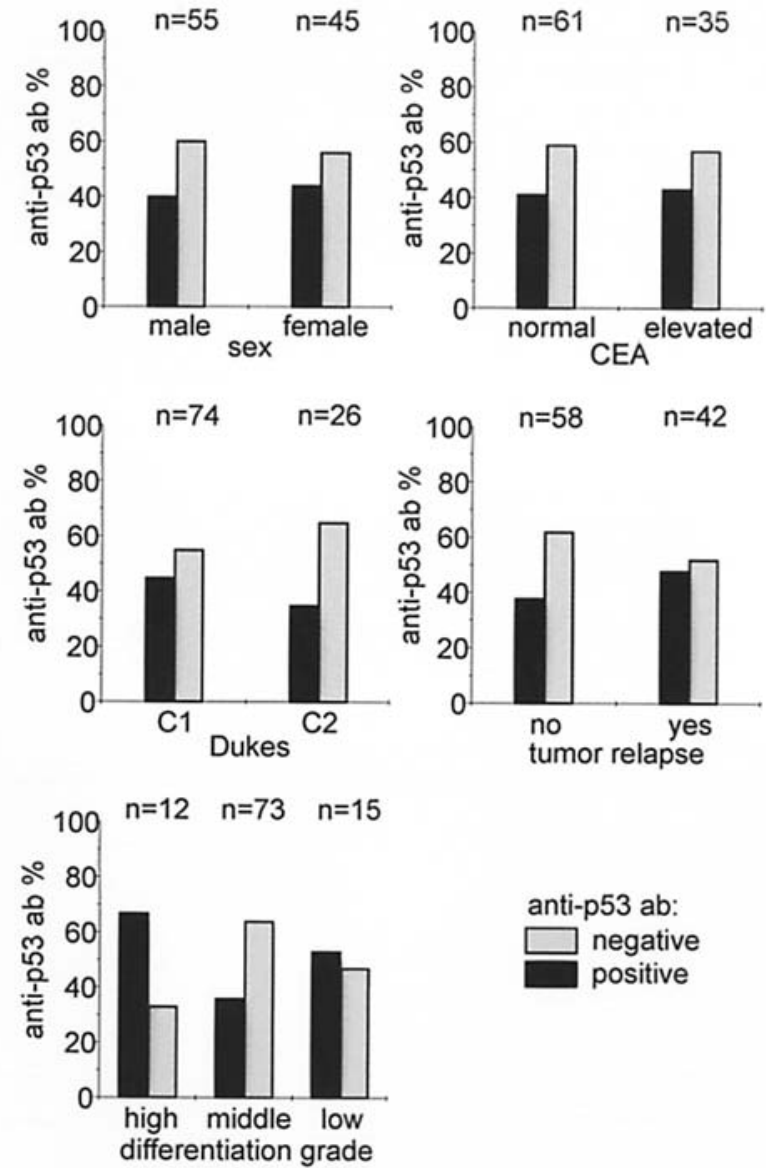

anti-p53 ab:

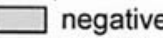
positive

Figure 2. Anti-p53 antibody status (anti-p53 ab) and clinical parameters in patients enrolled in the prospective Vienna colon cancer trial. There was an equal distribution of anti-p53 ab positive and anti-p53 ab negative patients, regardless of sex, elevation of CEA, Dukes stage, tumor relapse and differentiation grade. 

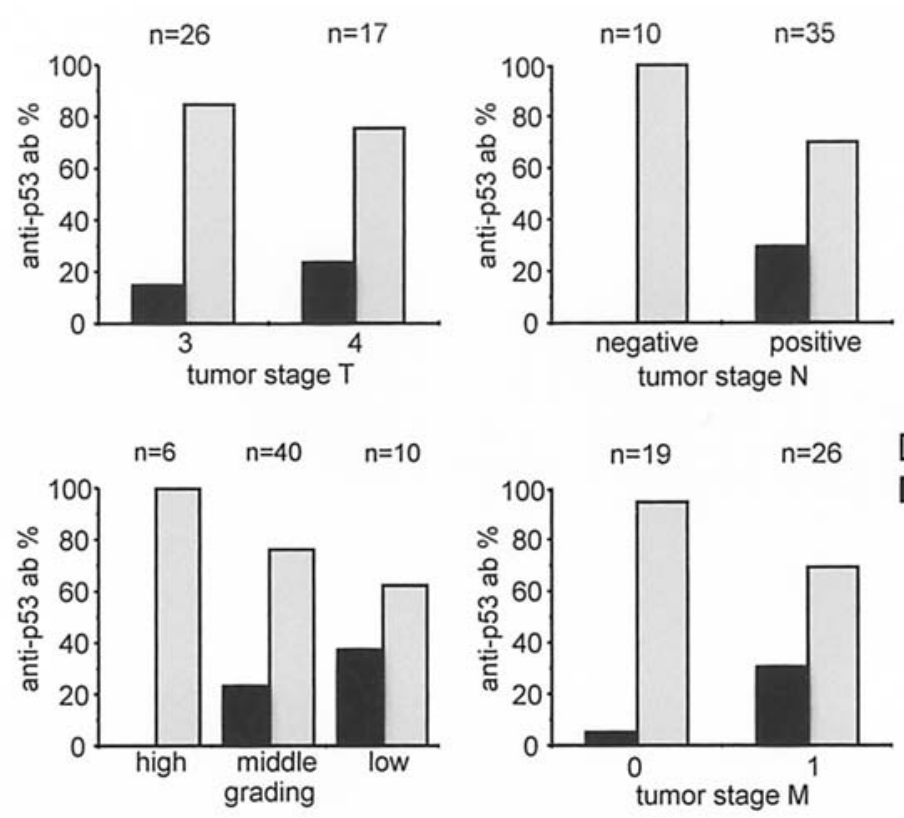

Figure 3. TNM classification and anti-p53 antibodies (anti-p53 ab) in patients with colon cancer who had been treated at the University of Heidelberg. Tumor stage T1 ( $\mathrm{n}=1$ patient) and tumor stage T2 $(\mathrm{n}=1)$ have not been included in this figure due to small numbers.

hepatocellular carcinoma (Wilcoxon: $\mathrm{p}<0.135$, log-rank: $\mathrm{p}<0.098$ ) and patients with breast cancer (Wilcoxon: $\mathrm{p}<0.125$, log-rank: $\mathrm{p}<0.138$ ) who were anti-p53 seropositive (Fig. 1). In the other tumor entities which were analyzed, no difference in survival between anti-p53 antibody positive and anti-p53 antibody negative patients was observed.

In parallel Kaplan-Meier analyses were performed for the established tumor markers. A positive correlation between an increase of the specific marker above normal range and a poor prognosis was seen in patients with gastric cancer (Wilcoxon: $\mathrm{p}<0.008, \log$-rank: $\mathrm{p}<0.02$ ), colon cancer (Wilcoxon: $\mathrm{p}<0.02$, log-rank: $\mathrm{p}<0.004$ ) and breast cancer (Wilcoxon: $\mathrm{p}<0.11$, log-rank: $\mathrm{p}<0.03$ ), whereas no correlation was found with the conventional tumor markers for patients with esophageal cancer (Wilcoxon: $\mathrm{p}<0.3$, log-rank: $\mathrm{p}<0.4$ ), rectal cancer (Wilcoxon: $\mathrm{p}<0.5$, log-rank: $\mathrm{p}<0.2$ ), pancreatic cancer (Wilcoxon: $\mathrm{p}<0.8, \log$-rank: $\mathrm{p}<0.9$ ) and hepatocellular carcinoma (Wilcoxon: $\mathrm{p}<0.14$, log-rank: $\mathrm{p}<0.19$ ).

Multivariate survival analysis. Multivariate survival analysis was carried out in the colon cancer patients from the Vienna prospective trial. The occurrence of anti-p53 antibodies was not related to a difference in survival (Wilcoxon: $\mathrm{p}<0.88$, log-rank: $\mathrm{p}<0.72$ ). Rather, tumor relapse represented the most powerful prognostic factor in these analyses (Wilcoxon: $\mathrm{p}<0.0001$, log-rank: $\mathrm{p}<0.0001$ ); low grade of differentiation (Wilcoxon: not significant, log-rank: $\mathrm{p}<0.06$ ) and Dukes stage C2 tumors (Wilcoxon: $\mathrm{p}<0.08$, log-rank: $\mathrm{p}<0.1$ ) were associated with a poorer prognosis.

Anti-p53 antibodies and clinical parameters. Fig. 2 shows the correlation of anti-p53 antibodies and clinical parameters in the Vienna prospective trial. The occurrence of anti-p53 antibodies was equally distributed in patients with elevated CEA and with negative CEA, in patients with and without tumor relapse, and in patients with stage Dukes $\mathrm{C} 1$ and $\mathrm{C} 2$.
The presence of anti-p53 antibodies in the patients' sera was not related to the differentiation grade of the colon cancer. In applying a Cox's proportional hazards model, there was no significant correlation between the anti-p53 antibody response and these variables.

Fig. 3 illustrates the results obtained for the patient group with colon cancer that had been seen at the University of Heidelberg. The occurrence of anti-p53 antibodies was observed both in patients with low tumor stage and in patients with high tumor stage. However, for tumor stage T1 there only was one patient who was anti-p53 antibody seropositive. There was a trend towards a higher percentage of anti-p53 antibody positive patients with higher tumor stages, (N2 and N3), in patients with low differentiation grade and in patients with metastasizing tumors; however these correlations were not statistically significant.

Anti-p53 antibodies during the course of malignant disease. In 303 of 591 patients with malignant disease 836 repeated measurements were carried out. In analyzing the anti-p53 antibody status during the course of malignant disease we found that a change over time from an anti-p53 negative status to an anti-p53 positive status rarely occurred. Only $3.6 \%(11 / 303)$ of the patients, whose follow-up was monitored showed a change from a negative to a positive anti-p53 antibody status. Likewise, a change from a positive to a negative anti-p53 antibody test was observed in only $3.6 \%(11 / 303)$ of patients with repeated measurements (Table IV).

With respect to conventional tumor markers the occurrence of a change from a negative to a positive test ranged from $0 \%$ in pancreatic cancer patients $(0 / 12)$ and in hepatocellular carcinoma patients $(0 / 20)$ up to $12.4 \%(17 / 137)$ in those with colon cancer. In total $9.9 \%$ (29/293) of the patients underwent a change of the respective conventional tumor marker. A seroconversion from a positive to a negative tumor marker test occurred in $6.1 \%(18 / 293)$ of the patients with a range 
Table IV. Status of anti-p53 antibodies and conventional tumor markers during the course of malignant disease.

\begin{tabular}{|c|c|c|c|c|c|c|c|c|c|}
\hline Tumor & Esophagus & Gastric & Colon & Rectum & Pancreas & $\mathrm{HCC}^{\mathrm{c}}$ & Breast & Urogenital & Total \\
\hline Anti-p53 & $9.1 \%$ & $1.9 \%$ & $2.9 \%$ & $6.5 \%$ & $8.3 \%$ & $0 \%$ & $3.6 \%$ & $10 \%$ & $3.6 \%$ \\
\hline $\begin{array}{l}\text { antibodies } \\
0 \rightarrow 1^{\mathrm{a}}\end{array}$ & $1 / 11$ & $1 / 54$ & $4 / 137$ & $2 / 31$ & $1 / 12$ & $0 / 20$ & $1 / 28$ & $1 / 10$ & $11 / 303$ \\
\hline Anti-p53 & $0 \%$ & $3.7 \%$ & $3.6 \%$ & $6.5 \%$ & $0 \%$ & $5.0 \%$ & $3.6 \%$ & $0 \%$ & $3.6 \%$ \\
\hline $\begin{array}{l}\text { antibodies } \\
1 \rightarrow 0^{\mathrm{b}}\end{array}$ & $0 / 11$ & $2 / 54$ & $5 / 137$ & $2 / 31$ & $0 / 12$ & $1 / 20$ & $1 / 28$ & $0 / 10$ & $11 / 303$ \\
\hline $\begin{array}{l}\text { Conventional } \\
\text { tumor marker } \\
0 \rightarrow 1^{\mathrm{a}}\end{array}$ & $\begin{array}{c}9.1 \% \\
1 / 11 \\
(\mathrm{SCC})^{\mathrm{d}}\end{array}$ & $\begin{array}{c}13 \% \\
7 / 54 \\
(\mathrm{CA} 72-4)^{\mathrm{e}}\end{array}$ & $\begin{array}{l}12.4 \% \\
17 / 137 \\
(\mathrm{CEA})^{\mathrm{f}}\end{array}$ & $\begin{array}{c}3.2 \% \\
1 / 31 \\
(\mathrm{CEA})^{\mathrm{f}}\end{array}$ & $\begin{array}{c}0 \% \\
0 / 12 \\
(\mathrm{CA} 19-9)^{\mathrm{g}}\end{array}$ & $\begin{array}{c}0 \% \\
0 / 20 \\
(\mathrm{AFP})^{\mathrm{h}}\end{array}$ & $\begin{array}{c}7.1 \% \\
2 / 28 \\
(\mathrm{CEA})^{\mathrm{f}} \\
3.6 \% \\
1 / 28 \\
(\mathrm{CA} 15-3)^{\mathrm{i}}\end{array}$ & $\begin{array}{c}\text { No marker } \\
\text { available }\end{array}$ & $\begin{array}{c}9.9 \% \\
29 / 293\end{array}$ \\
\hline $\begin{array}{l}\text { Conventional } \\
\text { tumor marker } \\
1 \rightarrow 0^{\mathrm{b}}\end{array}$ & $\begin{array}{c}18.2 \% \\
2 / 11 \\
(\mathrm{SCC})^{\mathrm{d}}\end{array}$ & $\begin{array}{c}5.6 \% \\
3 / 54 \\
(\mathrm{CA} 72-4)^{\mathrm{e}}\end{array}$ & $\begin{array}{c}1.5 \% \\
2 / 137 \\
(\mathrm{CEA})^{\mathrm{f}}\end{array}$ & $\begin{array}{c}3.2 \% \\
1 / 31 \\
(\mathrm{CEA})^{\mathrm{f}}\end{array}$ & $\begin{array}{c}0 \% \\
0 / 12 \\
(\mathrm{CA} 19-9)^{\mathrm{g}}\end{array}$ & $\begin{array}{c}20 \% \\
4 / 20 \\
(\mathrm{AFP})^{\mathrm{h}}\end{array}$ & $\begin{array}{c}7.1 \% \\
2 / 28 \\
(\mathrm{CEA})^{\mathrm{f}} \\
14.3 \% \\
4 / 28 \\
(\mathrm{CA} 15-3)^{\mathrm{i}}\end{array}$ & $\begin{array}{c}\text { No marker } \\
\text { available }\end{array}$ & $\begin{array}{c}6.1 \% \\
18 / 293\end{array}$ \\
\hline
\end{tabular}

${ }^{\mathrm{a}} 0 \rightarrow 1$, a change from a seronegative to a seropositive test result during follow-up; ${ }^{\mathrm{b}} 1 \rightarrow 0$, a change from a seropositive to a seronegative test result during follow-up; chepatocellular carcinoma; ${ }^{\mathrm{d}}$ squamous cell carcinoma; ${ }^{\mathrm{e}}$ cancer antigen 72-4; ${ }^{\mathrm{f}}$ carcinoembryonic antigen; ${ }^{\mathrm{g}}$ carbohydrate antigen 19-9; ${ }^{\mathrm{h}}$ alpha-fetoprotein; ${ }^{\mathrm{i}}$ cancer antigen 15-3. In 303 of 591 patients with malignant disease 836 repeated measurements were carried out during a median follow-up time of 188 days (minimum 1 day, maximum 1462 days). The anti-p53 antibody status changed in $7.2 \%$ (22/303) of the patients, whereas the conventional tumor markers showed an overall change in 16\% (47/293) of the patients.

from $0 \%(0 / 12)$ in pancreatic cancer patients, $1.5 \%(2 / 137)$ in colon cancer patients and up to $20 \%(4 / 20)$ in breast cancer patients. Thus, the presence of anti-p53 antibodies proved to be the more stable parameter.

Overall the anti-p53 antibody status changed in 22 of 303 (7.2\%) patients who were monitored. In $68.2 \%$ of these cases $(15 / 22)$ there was a correlation of seroconversion from a positive to a negative anti-p53 antibody status with surgical tumor reduction or a correlation of a change from a negative to a positive anti-p53 antibody test with tumor progression.

\section{Discussion}

In this study we have analyzed 1438 serum samples from patients with different types of malignant disease and 436 serum samples from patients without evidence of malignant disease. Our goal was to evaluate the diagnostic and clinical usefulness of the anti-p53 antibody response as a serological marker.

Anti-p53 antibodies were found in $23.4 \%$ of the sera of patients with all types of malignant disease tested with a sensitivity range from 11.5 to $34 \%$. The highest positivity rates were observed in colon $(31.9 \%)$ and breast cancer $(34 \%)$. This is in accordance with two large studies who showed the highest prevalence of anti-p53 antibodies in sera of colon- and breast cancer patients $(28,29)$. However, this maximum sensitivity of $34 \%$ prohibits the use of the anti-p53 antibody test to screen asymptomatic patients or patients without specific cancer risk. Of note, an antibody response occurred only in patients with malignant disease. Thus, the anti-p53 antibody test has a specificity of $100 \%$ for detection of malignancy.

The occurrence of antibodies against p53 is independent of the elevation of conventional tumor markers. In each tumor type investigated, we identified a subset of patients who were negative for established tumor markers but positive for anti-p53 antibodies. The percentage of additionally detected cancer patients varied depending on the sensitivity of the anti-p53 antibody test for the respective kind of tumor. Regarding breast cancer patients, $43 \%$ of those who were CEA and CA15-3 negative could be identified by testing for anti-p53 antibodies. In colon cancer patients, the percentage was $35 \%$, in hepatocellular carcinoma patients $24 \%$. The combination of the anti-p53 antibody test and measurement 
of established tumor markers led to a significant increase in sensitivity and a 6-11\% gain of information without reduction in specificity. Thus, the anti-p53 antibody test should be used as a complementary test in addition to measurement of established tumor markers in patients at high risk for specific types of cancer or with unclear results using conventional tumor markers. The increase in sensitivity without reduction in specificity constitutes the clinical relevance of anti-p53 antibody testing.

We showed a trend towards a poorer prognosis of anti-p53 antibody positive patients with breast cancer or hepatocellular carcinoma. These data, while not statistically significant, may indicate an unfavorable outcome in anti-p53 antibody positive patients.

Our investigation found no significantly elevated or decreased serum values for anti-p53 antibodies as a function of tumor type, TNM stage, histology, age, or degree. In our study anti-p53 antibodies occurred in early as well as in late stage colon tumors. The relationship to metastatic disease showed a trend towards a higher prevalence of anti-p53 antibodies in patients with more advanced colon cancers (tumor stages T2 and T3, low differentiation grade and metastasizing tumors). This is in accordance with previously published data (30). The patients included in our study, suffering from colon cancer, had predominantly advanced disease, particularly there were no patients with stage A disease.

Serum anti-p53 antibodies have been shown to predate clinical diagnosis of certain tumors, such as angiosarcoma of the liver in workers with occupational exposure to vinyl chloride (31), lung cancer in smokers $(32,33)$ or development of cancer in an asbestosis cohort (21), and thus might be useful in identifying individuals at high cancer risk. Further analyses are needed to study patients with early stage disease or patients at high risk for the development of a specific kind of cancer.

In conclusion, no association between serum anti-p53 antibodies and other clinical/prognostic parameters was evident in this study. The relationship between circulating anti-p53 antibodies and prognostic and clinical parameters is controversial. There are studies which have reported the presence of anti-p53 antibodies to be an indicator of a poor prognosis in patients with colorectal (34), breast (35), esophageal (36), gastric (37), pancreatic (38), lung (39) and ovarian cancer (40). In contrast, others have reported contradictory results (41-47). A most recent study presented data that immunity to p53 may predict improved overall survival in patients with advanced stage ovarian cancer (48).

Biomarkers for early detection of solid tumors are urgently needed. So, how can the results in reports on anti-p53 antibodies and their clinicopathological associations be explained? The discovery of the p53 family network suggests that the p53 status of a tumor should no longer be regarded as the sole predictor of clinical outcome and therapeutic responsiveness. Recent results including our own (49-51) have revealed that p53 is not the only component in predicting prognosis and response to chemotherapy (52) but instead the status of a network that contains p53, p63 and p73. Our data clearly show the specificity of anti-p53 antibodies detected in the sera of patients with different types of cancer. In addition, specific anti-p73 antibodies and specific anti-p63 antibodies, unrelated to the presence of anti-p53 antibodies, have been detected in sera of patients with various types of cancer (53). These results indicate that there is a specific immune response towards the three proteins. The complexity of the p53 family network and of the immune response towards its proteins may explain the controversies regarding the clinical/prognostic relevance of antibodies against p53, being one member of this family. In conclusion, it is rather unlikely that the antibody response towards p53 in the sera of patients with malignant disease may be the sole predictor of the clinical course and survival.

The median follow-up time in our longitudinal analysis was six months. During this time the status of the conventional tumor markers changed in $16 \%$ (47/239) of the patients, whereas the anti-p53 antibody status changed in only $7.2 \%$ $(22 / 103)$ of the patients. In $68.2 \%(15 / 22)$ of these cases there was a correlation of a change in anti-p53 antibody status with clinical parameters, such that a seroconversion from a positive to a negative anti-p53 antibody status correlated with response towards chemotherapy and radiation or surgical tumor reduction or that a change from a negative to a positive anti-p53 antibody status correlated with tumor progression. However, in our prospective colon cancer trial, in which 100 patients with Dukes C colon cancer were included and followed over 5 years, the anti-p53 antibody test failed to predict recurrence of Dukes C1 and C2 tumors postoperatively. Based on these results, routine use of this bio-marker cannot be recommended in the monitoring of patients with malignant disease.

In conclusion, the anti-p53 antibody test identifies patients with malignant disease who are negative for conventional tumor markers. Due to its low sensitivity, the anti-p53 antibody test cannot be viewed as an independent marker unrelated to other established tumor markers, but has its utility when examined in conjunction with measurement of the established tumor markers. Due to its $100 \%$ specificity, the anti-p53 antibody test increases sensitivity without decreasing specificity when used in complementary testing with other indices.

\section{Acknowledgements}

We thank Thomas Bruckner for excellent statistical advice and Tanja Seltenreich for expert technical assistance. This work was supported by grants from the Tumorzentrum Heidelberg/Mannheim to M.M.

\section{References}

1. Vousden KH and Prives C: P53 and prognosis: new insights and further complexity. Cell 120: 7-10, 2005.

2. Mills AA: p53: link to the past, bridge to the future. Genes Dev 19: 2091-2099, 2005.

3. Poyurovsky MV and Prives C: Unleashing the power of p53: lessons from mice and men. Genes Dev 20: 125-131, 2006.

4. Soussi T, Caron DF and May P: Structural aspects of the p53 protein in relation to gene evolution. Oncogene 5: 945-952, 1990.

5. Soussi T, Ishioka C, Claustres M and Beroud C: Locus-specific mutation databases: pitfalls and good practice based on the p53 experience. Nat Rev Cancer 6: 83-90, 2006.

6. Lane DP and Benchimol S: p53: oncogene or anti-oncogene? Genes Dev 4: 1-8, 1990.

7. Oren M: p53: the ultimate tumor suppressor gene? FASEB J 6: 3169-3176, 1992. 
8. Harris CC and Hollstein M: Clinical implications of the p53 tumor-suppressor gene. N Engl J Med 329: 1318-1327, 1993.

9. Zalcenstein A, Stambolsky P, Weisz L, et al: Mutant p53 gain of function: repression of CD95(Fas/APO-1) gene expression by tumor-associated p53 mutants. Oncogene 22: 5667-5676, 2003.

10. Greenblatt MS, Bennett WP, Hollstein M and Harris CC: Mutations in the p53 tumor suppressor gene: clues to cancer etiology and molecular pathogenesis. Cancer Res 54: 4855-4878, 1994.

11. Spiotto MT, Fu YX and Schreiber H: Tumor immunity meets autoimmunity: antigen levels and dendritic cell maturation. Curr Opin Immunol 15: 725-730, 2003.

12. Crawford LV, Pim DC and Bulbrook RD: Detection of antibodies against the cellular protein p53 in sera from patients with breast cancer. Int J Cancer 30: 403-408, 1982.

13. Caron-de FC, May LF, Mouriesse H, Lemerle J, Chandrasekaran K and May P: Presence of circulating antibodies against cellular protein $\mathrm{p} 53$ in a notable proportion of children with B-cell lymphoma. Int J Cancer 39: 185-189, 1987.

14. Davidoff AM, Iglehart JD and Marks JR: Immune response to p53 is dependent upon p53/HSP70 complexes in breast cancers. Proc Natl Acad Sci USA 89: 3439-3442, 1992.

15. Schlichtholz B, Legros Y, Gillet D, et al: The immune response to $\mathrm{p} 53$ in breast cancer patients is directed against immunodominant epitopes unrelated to the mutational hot spot. Cancer Res 52: 6380-6384, 1992.

16. Volkmann M, Müller M, Hofmann WJ, et al: The humoral immune response to p53 in patients with hepatocellular carcinoma is specific for malignancy and independent of the alpha-fetoprotein status. Hepatology 18: 559-565, 1993.

17. Müller M, Volkmann M, Zentgraf $\mathrm{H}$ and Galle PR: Clinical implications of the p53 tumor-suppressor gene. N Engl J Med 330: 865, 1994

18. Volkmann M, Hofmann WJ, Müller M, et al: p53 overexpression is frequent in European hepatocellular carcinoma and largely independent of the codon 249 hot spot mutation. Oncogene 9: 195-204, 1994

19. Lubin R, Schlichtholz B, Teillaud JL, Garay E, Bussel A and Wild CP: p53 antibodies in patients with various types of cancer: assay, identification, and characterization. Clin Cancer Res 1: 1463-1469, 1995

20. Wu CM, Tang R, Chen JR, et al: Humoral response to p53 is associated with conserved domains II and IV mutations in human colorectal cancer: a case-control study in Taiwan. Oncol Rep 12: 1045-1051, 2004

21. Li Y, Karjalainen A, Koskinen H, et al: p53 autoantibodies predict subsequent development of cancer. Int J Cancer 114: 157-160, 2005.

22. Balogh GA, Mailo DA, Corte MM, et al: Mutant p53 protein in serum could be used as a molecular marker in human breast cancer. Int J Oncol 28: 995-1002, 2006.

23. Matlashewski G, Banks L, Pim D and Crawford L: Analysis of human p53 proteins and mRNA levels in normal and transformed cells. Eur J Biochem 154: 665-672, 1986.

24. Labrecque S, Naor N, Thomson D and Matlashewski G: Analysis of the anti-p53 antibody response in cancer patients. Cancer Res 53: 3468-3471, 1993.

25. Schlichtholz B, Tredaniel J, Lubin R, Zalcman G, Hirsch A and Soussi T: Analyses of p53 antibodies in sera of patients with lung carcinoma define immunodominant regions in the p53 protein. Br J Cancer 69: 809-816, 1994.

26. Stephen CW, Helminen P and Lane DP: Characterisation of epitopes on human p53 using phage-displayed peptide libraries: insights into antibody-peptide interactions. J Mol Biol 248: 58-78, 1995.

27. Saleh J, Kreissler-Haag D and Montenarh M: p53 autoantibodies from patients with colorectal cancer recognize common epitopes in the $\mathrm{N}$ - or C-terminus of p53. In J Oncol 25: 1149-1155, 2004.

28. Angelopoulou K, Diamandis EP, Sutherland DJ, Kellen JA and Bunting PS: Prevalence of serum antibodies against the p53 tumor suppressor gene protein in various cancers. Int J Cancer 58: 480-487, 1994.

29. Shimada H, Ochiai T and Nomura F: Titration of serum p53 antibodies in 1,085 patients with various types of malignant tumors: a multiinstitutional analysis by the Japan p53 Antibody Research Group. Cancer 97: 682-689, 2003.

30. Lechpammer M, Lukac J, Lechpammer S, Kovacevic D, Loda M and Kusic Z: Humoral immune response to p53 correlates with clinical course in colorectal cancer patients during adjuvant chemotherapy. Int J Colorectal Dis 19: 114-120, 2004.
31. Trivers GE, Cawley HL, De Benedetti VM, et al: Anti-p53 antibodies in sera of workers occupationally exposed to vinyl chloride. J Natl Cancer Inst 87: 1400-1407, 1995.

32. Lubin R, Zalcman G, Bouchet L, et al: Serum p53 antibodies as early markers of lung cancer. Nat Med 1: 701-702, 1995

33. Trivers GE, De Benedetti VM, Cawley H, et al: Anti-p53 antibodies in sera from patients with cronic obstructive pulmonary disease can predate a diagnosis of cancer. Clin Cancer Res 2: 1767-1775, 1996.

34. Kressner U, Glimelius, Bergstrom, Pahlman L, Larsson A and Lindmark G: Increased serum p53 antibody levels indicate poor prognosis in patients with colorectal cancer. Br J Cancer 77: 1848-1851, 1998.

35. Peyrat JP, Bonneterre J, Lubin R, Vanlemmens L, Fournier J and Soussi T: Prognostic significance of circulating P53 antibodies in patients undergoing surgery for locoregional breast cancer. Lancet 345: 621-622, 1995.

36. Shimada H, Nabeya Y, Okazumi S, et al: Prognostic significance of serum p53 antibody in patients with esophageal squamous cell carcinoma. Surgery 132: 41-47, 2002.

37. Maehara Y, Kakeji Y, Watanabe A, et al: Clinical implications of serum anti-p53 antibodies for patients with gastric carcinoma. Cancer 85: 302-308, 1999.

38. Ohshio G, Suwa H and Imamura M: Clinical implication of anti-p53 antibodies and p53-protein in pancreatic disease. Int $\mathbf{J}$ Gastrointest Cancer 31: 129-135, 2002.

39. Murray PV, Soussi T, O'Brien ME, et al: Serum p53 antibodies: predictors of survival in small-cell lung cancer? Br J Cancer 83: $1418-1424,2000$.

40. Abendstein B, Marth C, Muller-Holzner E, Wildschwendter M, Daxenbichler G and Zeimt AG: Clinical significance of serum and ascitic p53 autoantibodies in epitelial ovarian carcinoma. Cancer 88: 1432-1437, 2000

41. Winter SF, Minna JD, Johnson BE, Takahashi T, Gazdar AF and Carbone DP: Development of antibodies against p53 in lung cancer patients appears to be dependent on the type of p53 mutation. Cancer Res 52: 4168-4174, 1992.

42. Angelopoulou K, Stratis M and Diamandis EP: Humoral immune response against p53 protein in patients with colorectal carcinoma. Int J Cancer 70: 46-51, 1997.

43. Mitsudomi T, Suzuki S, Yatabe, et al: Clinical implications of p53 autoantibodies in the sera of patients with non-small-cell lung cancer. J Natl Cancer Inst 90: 1563-1568, 1998.

44. Parasole R, Izzo F, Perrone F, et al: Prognostic value of serum biological markers in patients with hepatocellular carcinoma. Clin Cancer Res 7: 3504-3509, 2001

45. Tang R, Ko MC, Wang JY, et al: Humoral response to p53 in human colorectal tumors: a prospective study of 1,209 patients. Int J Cancer 94: 859-863, 2001.

46. Hogdall EV, Hogdall CK, Blaakaer J, et al: P53 autoantibodies in sera from Danish ovarian cancer patients and their correlation with clinical data and prognosis. APMIS 110: 545-553, 2002.

47. Chang SC, Lin JK, Lin TC and Liang WY: Genetic alteration of p53, but not overexpression of intratumoral p53 protein, or serum p53 antibody is a prognostic factor in sporadic colorectal adenocarcinoma. Int J Oncol 26: 65-75, 2005.

48. Goodell V, Salazar LG, Urban N, et al: Antibody immunity to the p53 oncogenic protein is a prognostic indicator in ovarian cancer. J Clin Oncol 24: 762-768, 2006.

49. Ramadan S, Terrinoni A, Catani MV, et al: p73 induces apoptosis by different mechanisms. Biochem Biophys Res Commun 331: 713-717, 2005.

50. Gressner O, Schilling T, Lorenz K, et al: TAp63alpha induces apoptosis by activating signaling via death receptors and mitochondria. EMBO J 24: 2458-2471, 2005.

51. Müller M, Schilling T, Sayan AE, et al: TAp73/DeltaNp73 influences apoptotic response, chemosensitivity and prognosis in hepatocellular carcinoma. Cell Death Differ 12: 1564-1577, 2005.

52. Russo A, Bazan V, Iacopetta B, Kerr D, Soussi T and Gebbia N: The TP53 colorectal cancer international collaborative study on the prognostic and predictive significance of p53 mutation: influence of tumor site, type of mutation, and adjuvant treatment. J Clin Oncol 23: 7518-7528, 2005.

53. Tominaga O, Unsal K, Zalcman G and Soussi T: Detection of p73 antibodies in patients with various types of cancer: immunological characterization. Br J Cancer 84: 57-63, 2001. 